\title{
Technological Innovation of Small and Medium Enterprises in Kosovo: Challenges and Barriers
}

\author{
Valon Kastrati ${ }^{1} \mathrm{PhD}$ candidate
}

\begin{abstract}
the ability to innovate, is the main challenge in the fast changing global markets, to maintain a stable economic development in the long term. The ICT can carry strategic incentives to adjust the economic structure and to modify the economic model of a country. This process can build a resource-saving and a environmentally friendly society. The technological innovation can improve the international competitiveness of the economy and the overall employment rate of young generations. The rapid development of SMEs has become a major force to support economic growth of Kosovo. However, small and medium enterprises in transitional economies are not always trusting technological innovation. Several businesses due to multiple internal and external environmental factors, show a low level of confidence over technological innovation. In fact, from an internal point of view, the management can be afraid of security issues, like leak of strategic information, or moreover company secrets. The typical example can be the reluctance to adopt cloud technology platforms to improve the management tasks and operations. Meanwhile the external threat can be an overturn of the management style that threatens positions and hierarchy within the organization.

This paper aims to analyze some key factors that prevent the spread of technological enhancement in small and medium enterprises in Kosovo.

Some typical case studies will be analyzed and further policy recommendations will be suggested.
\end{abstract}

Keywords: SME, ICT, confidence, success, transition economy.

\section{Introduction}

The penetration of Information and Communication Technology in the management of SME's is substantial in the global economy. The way it is changing the business model is very dynamic and for the moment it is very difficult to determine if there are delimited frontiers to the ICT applications for business purposes. Let us think just to the 3D printing, how it can overturn the traditional business model. Nevertheless in some parts of the world, like the new born Republic of Kosovo, the diffusion of recent technologies is still relatively slow, especially if we consider the SME sector, when traditional culture of doing business still prevails. The world market is developing so fast that even if the local enterprises are just interested in the neighborhood commercialization, the global competitors will soon nock at your local marketplace swiping away, may be decades of business establishment. 
Anyway to specific manufacturing sectors and processes, sometimes the intensive or recent technology can't bring any further improvement, if not can create inferior quality standards. Possible examples are EU certifications like PDO, PGI (Bureau 2003), where implementation of traditional (or primitive) technology is the key to the success (Mora 2009). This principles can apply easily to agricultural firms, or agro-industrial firms. Anyway other artesian manufacturers can benefit from this "competitive" slow motion technology of production. When it comes to trading gears, should not be any reasonable impediment to the firm from using social media to promote the goods, or to use cloud computing to manage sales, HR, website analytics, data intelligence etc. So the basic question is to what extend the Information Technology can be benefic to the company growth? What are the limits of applications, and what is the priority ranking of some recent technologies.

\section{Methodology}

We used mainly the information collected through 45 interviews of relatively successful SME entrepreneurs, and 38 interviews of failed or in process of failure entrepreneurs. The results were crosschecked between them in order to provide a better panorama of the potential ranking of priorities in the running of the SME.

The distribution of the interviews were mainly focused in the region of Pristina (23) and Peja (18) as described in figure 1, without excluding also the other regions from the survey. The size of the selected companies were less than 50 employers. This choice does not follow the World Bank definition (up to 99 employers), anyway due to the characteristics of this particular region other authors apply different definition measures of the SME's (Hauser, 2005).

$\square$ Pristina $\square$ Peja $\square$ Prizren $\square$ Dakovica $\square$ Gjilane $\square$ Mitrovica $\square$ Ferizaj

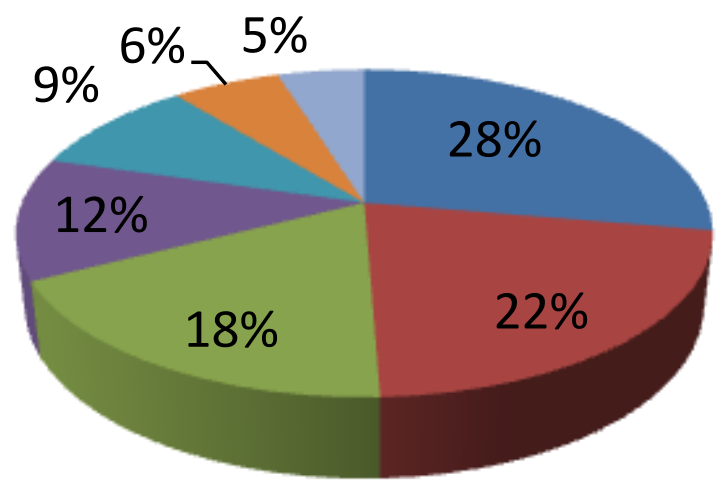

Figure 1. Geographical Distribution of the survey 
Pristina $\square$ Peja $\square$ Prizren $\square$ Dakovica $\backsim$ Gilane $\square$ Mitrovica $\square$ Ferizaj

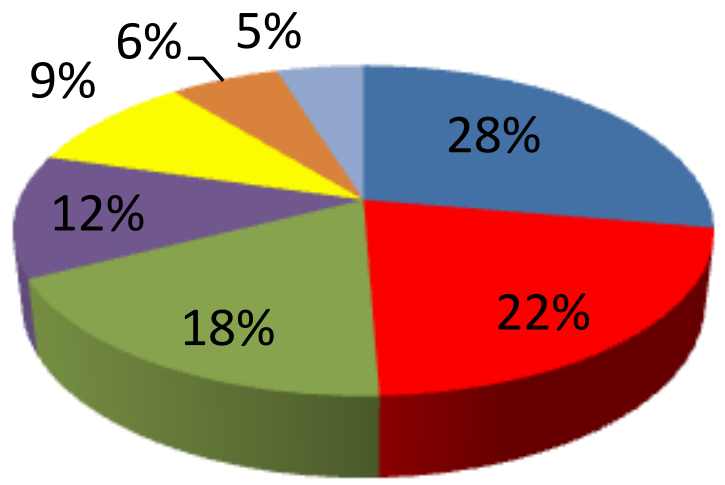

Figure 2. Distribution of SME's by Sector (survey)

In the second figure is showed the distribution of SME's by sector, trying to track a proxy of the population ratios. The main sector is the Service compartment with $38 \%$ of interviewed companies, the rest of the sectors is represented by close ratio between $12 \%$ Construction and $18 \%$ Transport.

Table 1. Responses to the question if the company is implementing the following technology ( $\%$ of Yes)

\begin{tabular}{|c|c|c|}
\hline Technological Tool & $\begin{array}{l}\text { Group } A^{1} \\
(\%)\end{array}$ & $\begin{array}{l}\text { Group } B^{2} \\
(\%)\end{array}$ \\
\hline Communication & & \\
\hline a. Email & 64 & 57 \\
\hline b. Telephone & 100 & 100 \\
\hline c. Messengers/Chat & 45 & 38 \\
\hline d. Fax: & 46 & 57 \\
\hline Web technologies & & \\
\hline a. Company Web Page & 46 & 35 \\
\hline b. Web analytics & 33 & 19 \\
\hline c. E-commerce & 26 & 20 \\
\hline d. Social Networks & 63 & 45 \\
\hline e. Pay Pal & 26 & 20 \\
\hline f. Online Banking & 32 & 16 \\
\hline g. Mobile applications & 15 & 7 \\
\hline $\begin{array}{ll}\text { III. } & \text { Cloud Computing }\end{array}$ & & \\
\hline a. ERP system & 38 & 21 \\
\hline b. HR & 28 & 26 \\
\hline c. Pay-roll & 78 & 72 \\
\hline
\end{tabular}


${ }^{1}$ Companies having a positive revenue in the past 5 five years.

${ }^{2}$ Companies declared failed or in the process of failure.

Source: Survey data

\section{Results and Interpretation}

The main results of the survey are aggregated in Table 1 . It is clear that the diffusion of some communication tools is not under discussion any more, like the telephone and e-mail can be considered indispensable in the running of a SME or generally any kind of Business. In the area of communication technologies seem to be no significant difference between the ratios of group A and B. It is important to emphasize that in both groups there are still some $34 \%$ and $43 \%$ of companies that do not use e-mail for communications. The presence of agricultural firms to a certain extend is justified, but also some other firms like transport were ignoring email communication at all. Surprisingly the fax usage was more accentuated in the group B companies, may be as a sign of an obsolete technology.

Web Technologies reveal some important patterns of difference between the two groups. The main difference is the social network activity, that can be for communication purposes, marketing, public outreach, PR etc. The difference is about 18 points in percentage representing the very simple signal of a shifting business environment. It is important to note that some companies do not have any web page at all but they have a Facebook or Twitter account. The penetration of E-commerce is still at a premature status, due to some financial constraints that Kosovo is facing from the lack of full recognition as an independent state. This apply also to the E-banking, or PayPal applications. Finally some companies are adventuring in the mobile applications customized for their business, mainly in the group A $(15 \%)$.

\section{Typical constrains}

\subsection{The costs}

Generally the main obstacle to implement new technologies seems to be the cost of implementation, migration, running and maintenance. The SME's cannot cover the multiple burdens of implementing the technology. Generally the outsourcing seems to be the main solution (57\%) anyway some companies rely totally on their own resources, typically run by young entrepreneurs or young members of the family (family run business). The results of the table 2 show that the outsourcing of ICT implementation is completely indifferent between group $\mathrm{A}$ and $\mathrm{B}$. The main factor influencing the outsourcing component seems to be the geographical location. Companies located in Pristina seem to be more eager to utilize outsourcing resources rather than own. 
Table 2 Percent of firms using technology from outsourcing companies*

\begin{tabular}{|lll|}
\hline Region & Group $A^{1}$ & Group B \\
\hline Pristina & 62 & 69 \\
\hline Prizreni & 46 & 38 \\
\hline Ferizaj & 28 & 31 \\
\hline ĐAkovica & 35 & 33 \\
\hline Gnjilane & 38 & 39 \\
\hline Mitrovica & 32 & 30 \\
\hline Peja & 31 & 26 \\
\hline
\end{tabular}

*At least $5 \%$ of the total costs of the company

${ }^{1}$ Companies having a positive revenue in the past 5 five years.

${ }^{2}$ Companies declared failed or in the process of failure.

\subsection{Information Asymmetry}

The skepticism related to new technologies is a typical factor accompanying this global processes. From an internal point of view, the management can be concerned of security issues, like leak of strategic information, or moreover company secrets. Meanwhile the external threat can be an overturn of the management style that threatens business as usual culture within the organization. To the question if the security issues where a major concern to implementing ICT within the company Table 3, the responses where quite different from region to region. But Pristina $(28 \%)$ as a metropolitan capital had the tendency to be more confident, along Prizreni $(36 \%)$. Meanwhile the highest hesitation was in Gnjilane(61\%) considering a major concern the SME security, among running SME's. Considering that this is a subjective post occurrence question, the reliability of group B answers is to be evaluated with caution. Also from this table the main difference is just geographical location, meanwhile the difference between groups is still not significant.

\begin{tabular}{|c|c|c|}
\hline \multicolumn{3}{|c|}{$\begin{array}{l}\text { Table } 3 \text { Percent of firms answering YES } \\
\text { Is the security issue a major concern to implementing ICT within the company }\end{array}$} \\
\hline Region & Group $A^{1}$ & Grou \\
\hline Pristina & 28 & 34 \\
\hline Prizreni & 36 & 27 \\
\hline Ferizaj & 42 & 39 \\
\hline ĐAkovica & 38 & 39 \\
\hline Gnjilane & 61 & 46 \\
\hline Mitrovica & 57 & 43 \\
\hline Peja & 49 & 32 \\
\hline
\end{tabular}

${ }^{1}$ Companies having a positive revenue in the past 5 five years.

${ }^{2}$ Companies declared failed or in the process of failure.

\section{Conclusion}

The barriers to ICT implementation in Kosovo SME's are multiple, some of them relate directly to objective obstacles, like activation or maintenance costs, but some other barriers are directly connected to culture and lack of clear information about the potential settlement for the SME. Some significant benefits are confirming the thesis of 
ICT as a comparative advantage in the success of a SME. These advantages were more accentuated in the web technologies and the usage of social networks as powerful means of communication and outreach. The key factors of success and failure a SME are multiple, the aim of this study is just to show some comparative advantages of ICT implementation. Further investigation is needed to enlarge the sample size and to include other factors and relevant technologies that may influence the accomplishment of a SME growth.

A simple element is missing from the attention of this study is the life span of a SME. It was not in the intention of the study, anyway the presence of young and technologically equipped companies among group $\mathrm{B}$, was not excluded among the sample. Sometimes the life of these companies was less than one year, presenting an objection to the thesis that technology is an exclusive asset for the success.

\section{References}

Ruzzier, Mitja, Robert D. Hisrich, and Bostjan Antoncic. "SME internationalization research: past, present, and future." Journal of small business and enterprise development 13.4 (2006): 476-497.

Bureau, J. C., \& Valceschini, E. (2003). European food-labeling policy: successes and limitations. Journal of Food Distribution Research, 34(3), 70-76.

Mora, C., \& Menozzi, D. (2009). International marketing and trade of protected designation of origin products. International marketing and trade of quality food products, 61-82.

Hauser, M. (2005, November). A qualitative definition of SME. In SBS Expert Meeting-Towards better Structural Business and SME statistics, OECD, Paris.

Ayyagari, M., Beck, T., \& Demirguc-Kunt, A. (2007). Small and medium enterprises across the globe. Small Business Economics, 29(4), 415-434.

Krasniqi, B. A. (2007). Barriers to entrepreneurship and SME growth in transition: the case of Kosova. Journal of Developmental Entrepreneurship, 12(01), 71-94.

Hoxha, D. (2008). The performance of micro firms in Kosova: size, age and educational implications. International Journal of Globalisation and Small Business, 3(1), 25-40.

DOI: $10.1080 / 14631377.2010 .498687$

Bajçinca, E. (2014).The impact of firm size on access to bank loans - Kosovo case. International Scientific Conference, Albanian Studies Days, 1-4 may, 2014. (In Albanian Original, 2014). Albanian Study Days 2014. Proceedings of Conference, p 20-22. UET PRESS, Tirana.

Beck, Th. and Demirguc-Kunt, A. (February 2006). Small and Medium Size Enterprises: Acces to Finance as a Growth Constraint. Journal of Banking \& Finance, Volume 30, Issue 11, November 2006, Pages 2931-2943. doi:10.1016/j.jbankfin.2006.05.009.

BSC Kosovo, (2012). SME Survey database. Prishtina.

Krasniqi, B. A. (2012), Research methods in social science, Booklet. Institute for Entrepreneurship and Small Business, Prishtina. (Albanian Original, 2012).

Tmava, Q., Peci, F., Luboteni, G., (2013). The Role of Banks in Small and Medium Enterprises Financing: A Case Study from Kosovo. Journal of Financial Economics, 13(June), 187-222. doi:10.1016/0304405X(84). 